\title{
Testing a Transpiration Cooled Zirconium-Di-Boride sample in the Plasma Tunnel at IRS
}

\author{
Marc Ewenz Rocher*, Tobias Hermann ${ }^{\dagger}$, Matthew McGilvray ${ }^{\ddagger}$, Hassan Saad Ifti ${ }^{\S}$ \\ The University of Oxford, Department of Engineering Science, Osney Mead, The Southwell Building, \\ Oxford OX2 OES, United Kingdom
}

\author{
Fabian Hufgard ${ }^{\pi}$ Martin Eberhart"l, Arne Meindl*, Stefan Löhle ${ }^{\dagger \dagger}$ \\ Universität Stuttgart, Institut für Raumfahrtsysteme, Pfaffenwaldring 29, D70569 Stuttgart, Germany
}

\author{
Tommaso Giovannini括 Luc Vandeperre ${ }^{\S \S}$ \\ Imperial College London, Department of Materials $\&$ Centre for Advanced Structural Ceramics, \\ London $S W 7$ 2AZ, $U K$
}

\begin{abstract}
Transpiration cooling is an active thermal protection system (TPS), in which a coolant gas is fed through a porous material. This requires a material that stays structurally stable at high temperatures, while having the desired permeability. This paper explores transpiration cooling of Ultra-High-Temperature-Ceramics (UHTCs). A stagnation probe with transpiration cooled $\mathrm{ZrB}_{2}$ was tested in a plasma wind tunnel at a null point heat flux of $3.59 \mathrm{MW} / \mathrm{m}^{2}$ in steady state and transiently at $2 \mathrm{MW} / \mathrm{m}^{2}$. The aim is to understand whether transpiration cooling can increase the UHTC operating temperature by shielding it from oxygen and reducing the heating from surface re-combination. Several diagnostics are applied, including an Echelle spectrograph that explores outgassing of oxidation products from the surface. Infrared thermography is employed to track the surface temperature at the front and the back surface temperature is measured by a pyrometer. Furthermore, the Planck radiation background of the emission spectra is used to assess the front surface temperature. The testing included a variation in the injectant species and mass flux. While the uncooled sample fully oxidised at a surface temperature of $2150 \mathrm{~K}, 20.25 \mathrm{~g} / \mathrm{m}^{2} \mathrm{~s}$ of helium and $620.11 \mathrm{~g} / \mathrm{m}^{2} \mathrm{~s}$ of nitrogen prevented oxidation of the transpiration cooled samples. At a blowing parameter of 0.1094 , the helium cooled probe reached a front surface temperature of $1428 \mathrm{~K}$ and reduced the incident heat flux by $77 \%$ compared to the uncooled sample. The nitrogen cooled sample had a maximum front surface temperature of $1128 \mathrm{~K}$ with a blowing parameter of $\mathbf{1 . 9 5 8}$ and an $\mathbf{8 3 . 3} \%$ lower incident heat flux than the uncooled sample.
\end{abstract}

\footnotetext{
*PhD student, Hypersonics Group, Oxford Thermofluids Institute, AIAA Member. Email: marc.ewenzrocher@eng.ox.ac.uk ${ }^{\dagger}$ Post-doctoral Research Assistant, Hypersonics Group, Oxford Thermofluids Institute, AIAA Member.

¥Associate Professor, Head of Hypersonics Group, Oxford Thermofluids Institute, AIAA Member.

$\S \mathrm{PhD}$ student, Hypersonics Group, Oxford Thermofluids Institute, AIAA Member.

『PhD student, High Enthalpy Flow Diagnostics Group, Institute of Space Systems, AIAA Member.

" Post-doc, High Enthalpy Flow Diagnostics Group, Institute of Space Systems, AIAA Member.

**PhD student, High Enthalpy Flow Diagnostics Group, Institute of Space Systems, AIAA Member.

${ }^{\dagger \dagger}$ Research engineer, Head of High Enthalpy Flow Diagnostics Group, Institute of Space Systems, AIAA Member.

$\ddagger \ddagger$ Post-doctoral Research Assistant, Imperial College London.

$\S \S$ Professor of Structural Ceramics, Imperial College London.
} 


\section{Nomenclature}

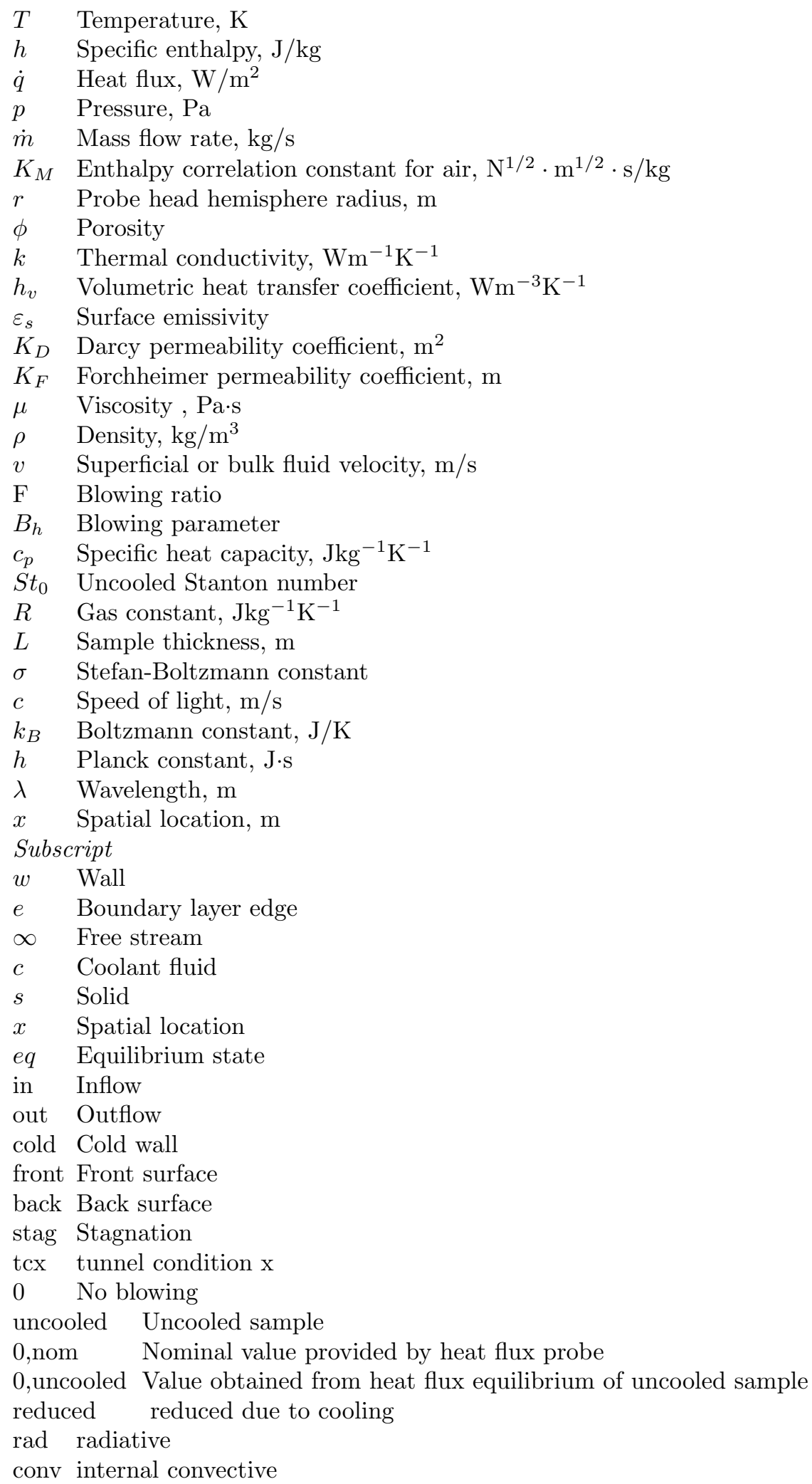




\section{Introduction}

When hypersonic vehicles fly through an atmosphere, they need a Thermal Protection System (TPS) to shield the payload from the searing heat around the capsule. ${ }^{1}$ In the past, they relied on thermal soaks ${ }^{2}$ with low thermal conductivity and high re-radiation or ablative heat shields. ${ }^{3}$ The latter additionally have a pyrolysis zone, which produces a driving gas that flows through the porous upper layers and cools them by convection while also mitigating incident heat flux through blowing.

Transpiration cooling is a promising new TPS, in which a coolant gas transpires a porous Ultra-HighTemperature-Ceramic (UHTC). It cools it down internally by convection and externally through film cooling, which creates a barrier between the searing hot shocked gas and the UHTC wall. ${ }^{4}$ It has the potential to enable fully re-usable, light TPSs that can sustain very high peak heat loads. Transpiration cooling is a key technology to realise sharp edge designs of hypersonic vehicles. Small radii of curvature, usually encountered at the leading edge, are very desirable from an aerodynamic viewpoint, ${ }^{5}$ but lead to high local heat fluxes of several $\mathrm{MW} / \mathrm{m}^{2}$. The key advantage of transpiration cooling over ablative heat shields is that it maintains the shape stability of these critical aerodynamic components. The first real flight concept validation was performed by SHEFEX II in June 2012 and showed that the surface temperature of a facet could successfully be lowered with up to $58 \%$ cooling efficiency. ${ }^{6}$

Currently, the most popular candidates for the transpiration cooled porous medium are Ultra-HighTemperature-Ceramics (UHTCs) ${ }^{4}$ or C/C composites. ${ }^{6}$ These materials are chosen for their high melting points, which promise a large passive cooling potential through re-radiation. $\mathrm{ZrB}_{2}$, a UHTC, for instance has a very high melting point of $3519 \mathrm{~K} .{ }^{7}$ However, significant oxidation of UHTCs occurs from $1000 \mathrm{~K}$ upwards. ${ }^{8}$ Oxidation products start blocking the pores and form an impermeable layer, ${ }^{9}$ while the virgin material recesses. This significantly limits the operating temperature and prevents the $\mathrm{ZrB}_{2}$ from achieving its full passive cooling potential. Since the radiative heat flux of a material is proportional to the fourth power of surface temperature, an increase of the operating temperature from $1000 \mathrm{~K}$ to $2500 \mathrm{~K}$ would entail an almost forty-fold increase in re-radiation.

This paper investigates whether transpiration cooling with helium and nitrogen can shield UHTCs from atmospheric oxygen, thus increasing the range of operation in terms of surface temperature and incident heat flux. A porous UHTC sample is tested in the IRS PWK4 plasma wind tunnel in an air free-stream. During testing, the front and rear surface temperatures of $\mathrm{ZrB}_{2}$, the coolant gas injection conditions and the emission spectra at the surface are measured. Additionally, a method to determine the stagnation point heat flux from the plenum pressure impulse response was applied. ${ }^{10}$ After plasma heating, the surfaces were observed in a SEM with the samples still in the holders. Subsequently the samples were removed, impregnated in a low viscosity epoxy and sectioned to investigate the cross-sections in the SEM using secondary electron imaging and energy dispersive x-ray spectroscopy.

\section{Experimental Setup}

The experiment took place in the PWK4 plasma wind tunnel at IRS in Stuttgart. ${ }^{11,12}$ Figure 2 shows the probe mount in the tunnel chamber. In the following, the operational characteristics of the plasma generator and the detailed probe design are presented.

\section{A. PWK4 Plasma Wind Tunnel and Conditions}

PWK 4, as shown in Fig. 3, is a continuous high-enthalpy facility that produces a steady-state plasma free jet and therewith allows the study of long duration thermochemical effects. It is equipped with the coaxial thermal arc-generator RB3 ${ }^{11}$ RB3 has a bi-throat geometry and injects the working gases in a two-stage process. While nitrogen is added close to the cathode, oxygen is injected further downstream to prevent the said cathode from oxidation. The gas is heated by an electric arc in the discharge chamber, before passing the second throat and accelerating through the nozzle.

A flow condition is characterised by the working gas mass flow, the generator power, the pressure in the vacuum chamber and the axial distance between the test object and the plasma generator. A traverse can re-position the probes during testing. Operation can be conducted for hours and provides a continuous thermochemical load to probes in the flow.

The tunnel was operated at three different conditions, as summarised in Table 1. All conditions refer to an artificial air plasma, which consisted of $76.85 \%$ nitrogen and $23.15 \%$ oxygen by mass and was modelled 


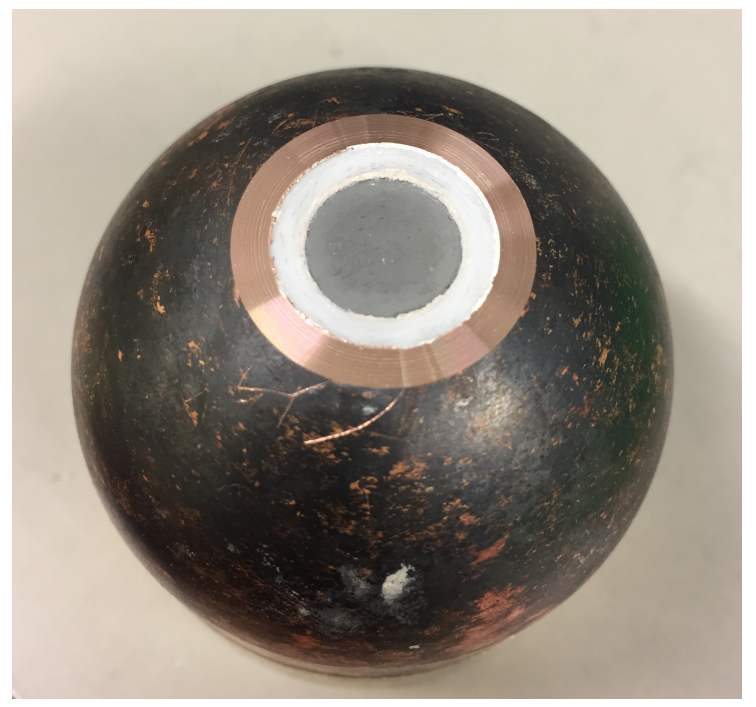

Figure 1: Porous UHTC sample sealed in the probe head before testing.

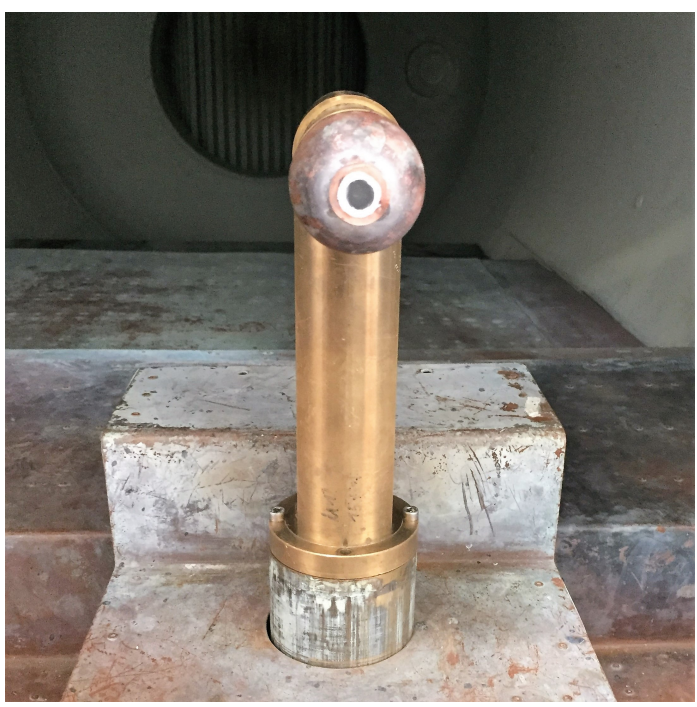

Figure 2: Probe head mounted in the PWK4 plasma wind tunnel.

as air. Conditions 1 and 2 were chosen as intermediate steps to carefully ramp up the heat flux and front surface temperature to the desired value. They had been replicated from previous experiments. ${ }^{12}$ Condition 4 was used for the NISIp calibrations, ${ }^{10}$ which identify the pressure impulse response of a system and later reconstruct the surface heat flux based on the plenum pressure history. The target front surface temperature for the uncooled sample was $2100 \mathrm{~K}$ - high enough to still be above the $1000 \mathrm{~K}$ oxidation threshold temperature in the cooled cases and low enough to account for the temperature limits of other probe components. This was achieved by using condition 2 as a starting point and slowly moving the probe closer to the nozzle. Condition 3 was reached at a distance of $178 \mathrm{~mm}$ between nozzle exit and probe head stagnation point.

Table 1: Overview of the test conditions in the PWK4 plasma wind tunnel.

\begin{tabular}{|c|c|c|c|c|c|}
\hline Tunnel Condition & 1 & 2 & 3 & 4 (NISIp) & Uncertainty \\
\hline Facility & PWK4 (RB3) & PWK4 (RB3) & PWK4 (RB3) & PWK4 (RB3) & \\
\hline$T_{\text {front; uncooled }}$ & $1400 \mathrm{~K}$ & $1600 \mathrm{~K}$ & $2150 \mathrm{~K}$ & $<550 \mathrm{~K}$ & $\pm 2 \%$ \\
\hline$h_{w}$ & $1.215 \mathrm{MJ} / \mathrm{kg}$ & $1.462 \mathrm{MJ} / \mathrm{kg}$ & $2.216 \mathrm{MJ} / \mathrm{kg}$ & $0.252 \mathrm{MJ} / \mathrm{kg}$ & \\
\hline$q_{0 ; \text { cold }}$ & $2 \mathrm{MW} / \mathrm{m}^{2}$ & $3 \mathrm{MW} / \mathrm{m}^{2}$ & $3.95 \mathrm{MW} / \mathrm{m}^{2}$ & $2 \mathrm{MW} / \mathrm{m}^{2}$ & $\pm 20 \%$ \\
\hline$h_{e}$ & $19.02 \mathrm{MJ} / \mathrm{kg}$ & $28.76 \mathrm{MJ} / \mathrm{kg}$ & $30.42 \mathrm{MJ} / \mathrm{kg}$ & $23.16 \mathrm{MJ} / \mathrm{kg}$ & \\
\hline$p_{\text {stag }}$ & $2035 \mathrm{~Pa}$ & $1970 \mathrm{~Pa}$ & $3220 \mathrm{~Pa}$ & $1250 \mathrm{~Pa}$ & $\pm 0.5 \%$ \\
\hline$p_{\text {static }}$ & $330 \mathrm{~Pa}$ & $275 \mathrm{~Pa}$ & $275 \mathrm{~Pa}$ & $30 \mathrm{~Pa}$ & $\pm 0.15 \%$ \\
\hline$T_{\mathrm{e}, \mathrm{eq}}$ & $5435 \mathrm{~K}$ & $5950 \mathrm{~K}$ & $6180 \mathrm{~K}$ & $5550 \mathrm{~K}$ & \\
\hline$c_{p, e}$ & $16695 \mathrm{Jkg}^{-1} \mathrm{~K}^{-1}$ & $17787 \mathrm{Jkg}^{-1} \mathrm{~K}^{-1}$ & $16023 \mathrm{Jkg}^{-1} \mathrm{~K}^{-1}$ & $19844 \mathrm{Jkg}^{-1} \mathrm{~K}^{-1}$ & \\
\hline$\dot{m}_{\infty}$ & $4.99 \mathrm{~g} / \mathrm{s}$ & $4.99 \mathrm{~g} / \mathrm{s}$ & $4.99 \mathrm{~g} / \mathrm{s}$ & $6.52 \mathrm{~g} / \mathrm{s}$ & $\pm 0.4 \%$ \\
\hline
\end{tabular}

The enthalpy was found from an empirical equation provided by Zoby: ${ }^{13}$

$$
h_{e}=K_{M} \dot{q}_{0} \sqrt{\frac{r}{p_{\text {stag }}}}+h_{w} .
$$

The hot gas equilibrium temperature was calculated with the Chemical Equilibrium with Applications online tool ${ }^{14}$ in a tp problem type. For a known pressure the hot gas temperature was varied until the stagnation enthalpy was matched. 


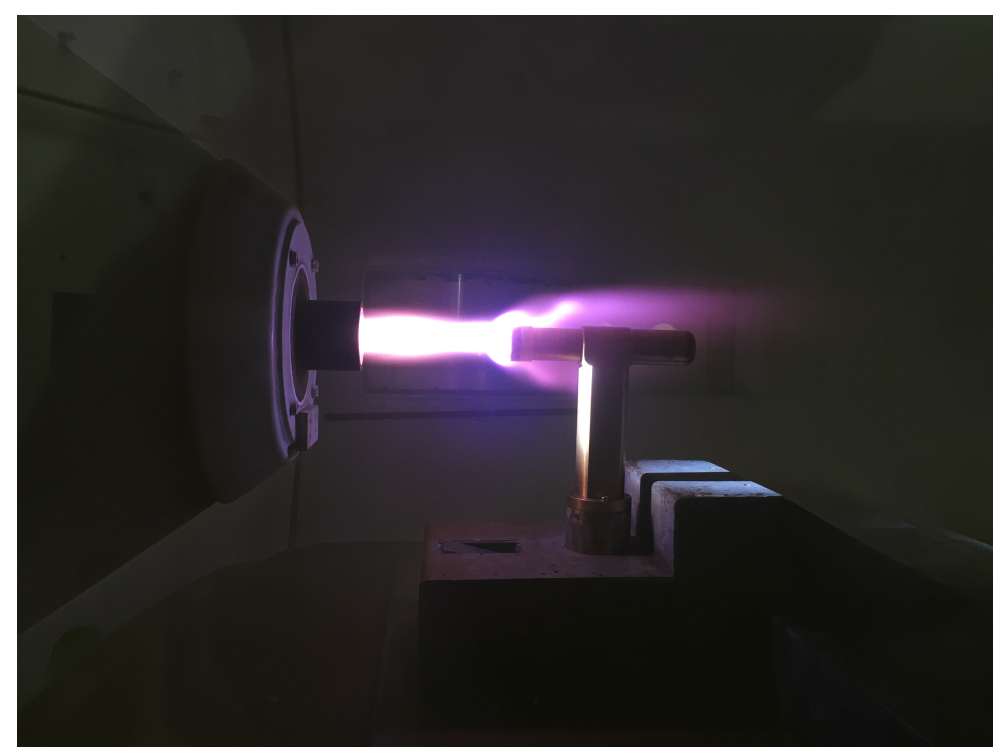

Figure 3: Picture of the probe in an air plasma stream in PWK 4.

\section{B. Probe Design}

The probe was designed to house the porous $\mathrm{ZrB}_{2}$ sample while it is exposed to the desired thermal loads. It consists of a hemispherical copper head, a pyrometer mount and a brass adapter. The probe design is depicted in Fig. 4, with an exploded $\mathrm{CAD}$ view. $\mathrm{A} \mathrm{ZrO}_{2}$ insulation ring mitigates the lateral heat flux from the hot $\mathrm{ZrB}_{2}$ to the water cooled copper. It has a low thermal conductivity of about $2 \mathrm{~W} / \mathrm{mK} \pm 0.5$ $\mathrm{W} / \mathrm{mK}^{15}$ The $\mathrm{ZrB}_{2}$ sample has a front diameter of $10.6 \mathrm{~mm}$ and a draft angle of $3^{\circ}$. It has a porosity of $(42 \pm 1) \%$, thermal conductivity of $k_{s}=48 \pm 1 \mathrm{Wm}^{-1} \mathrm{~K}^{-1}$ and a surface emissivity of $\varepsilon_{s}=0.75 .{ }^{16}$ The volumetric heat transfer coefficient is assumed to be $h_{v}=5 \times 10^{4} \mathrm{Wm}^{-3} \mathrm{~K}^{-1}$. Both parts are glued into the stagnation point of the copper head with a ultra-high temperature adhesive. For the adhesive, Aremco 516 was chosen for the uncooled probe for its ultra high operating temperature, whereas Glassbond Sauereisen Zircon Potting Cement No. 13RW was chosen for its superior sealing properties in the cooled probes. During the experiment, the probe chamber is pressurised with the used coolant, which is fed in from a gas supply outside of the facility. The Optris CT 1MH1 CF pyrometer measures temperatures in the range of $1073 \mathrm{~K}$ to $2473 \mathrm{~K}$ from the sample backside. It has a system accuracy of $\pm(0.3 \%$ of reading $+2 \mathrm{~K})$. The distance to the surface amounted to $24.5 \mathrm{~mm}$, which corresponds to a spot size of $5.4 \mathrm{~mm}$.

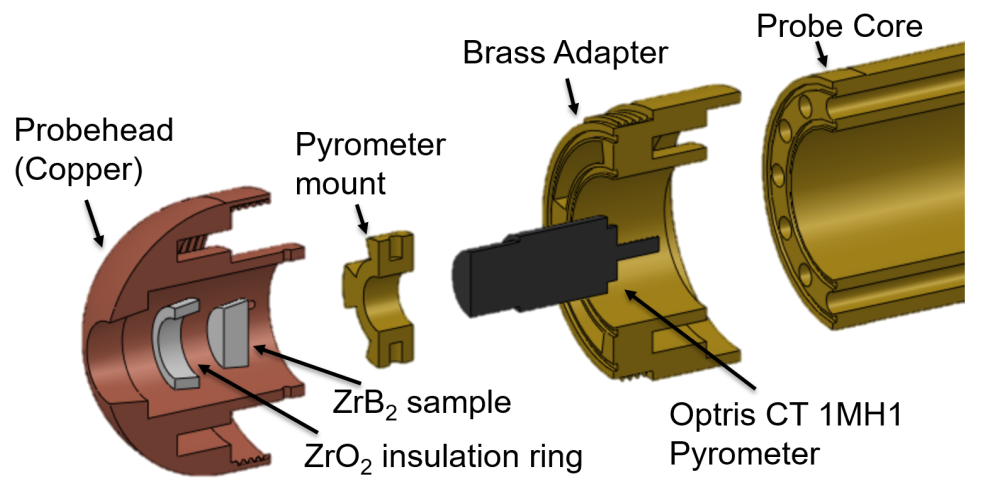

Figure 4: Exploded CAD schematic of the probe.

The experimental setup of the instrumentation is shown in Fig. 5. An Omega PXM-319 absolute 0-15 bar pressure sensor records the transient pressure behind the sample with $0.25 \%$ accuracy. An Aryelle 150 UV-VIS-NIR echelle spectrometer records $20 \mathrm{spectra} / \mathrm{s}$ at an exposure time of $50 \mathrm{~ms}$ and a spectral resolution 
of 29241 in the range of $249.9333 \mathrm{~nm}$ to $884.5532 \mathrm{~nm}$. The $\mathrm{ZrB}_{2}$ front surface temperature in the uncooled cases was measured by a FLIR A6751sc Midwave Infrared camera at $33.33 \mathrm{~Hz}$ for condition 1 and 2 and at $8.33 \mathrm{~Hz}$ for condition 3. It operates in the $3.0 \mu \mathrm{m}-5.0 \mu \mathrm{m}$ waveband and has a pixel resolution of $640 \times 512$. A LumaSense MCS640 Thermal Imager was employed to measure the front surface temperature of the cooled cases. It operates in the 978-1559 K temperature range and recorded 3 frames/s in the helium test (Probe \#2) and 15 frames/s in the nitrogen test (Probe \#5). The mass flow controller was a Tylan 2900 Series operated by an in-house flow regulator.

The sample is calibrated as a heat flux gauge using the non-integer system identification approach for plenum pressure. ${ }^{17}$ The sample's surface is heated by a laser with a maximum optical power of $540 \mathrm{~W}$ at $980 \mathrm{~nm}$ (Laserline LDM500-100) and both the input power and the transient plenum pressure signal are recorded with a LeCroy $24 \mathrm{Xs}-\mathrm{A}$ oscilloscope. More details can be obtained in Ref. ${ }^{10}$

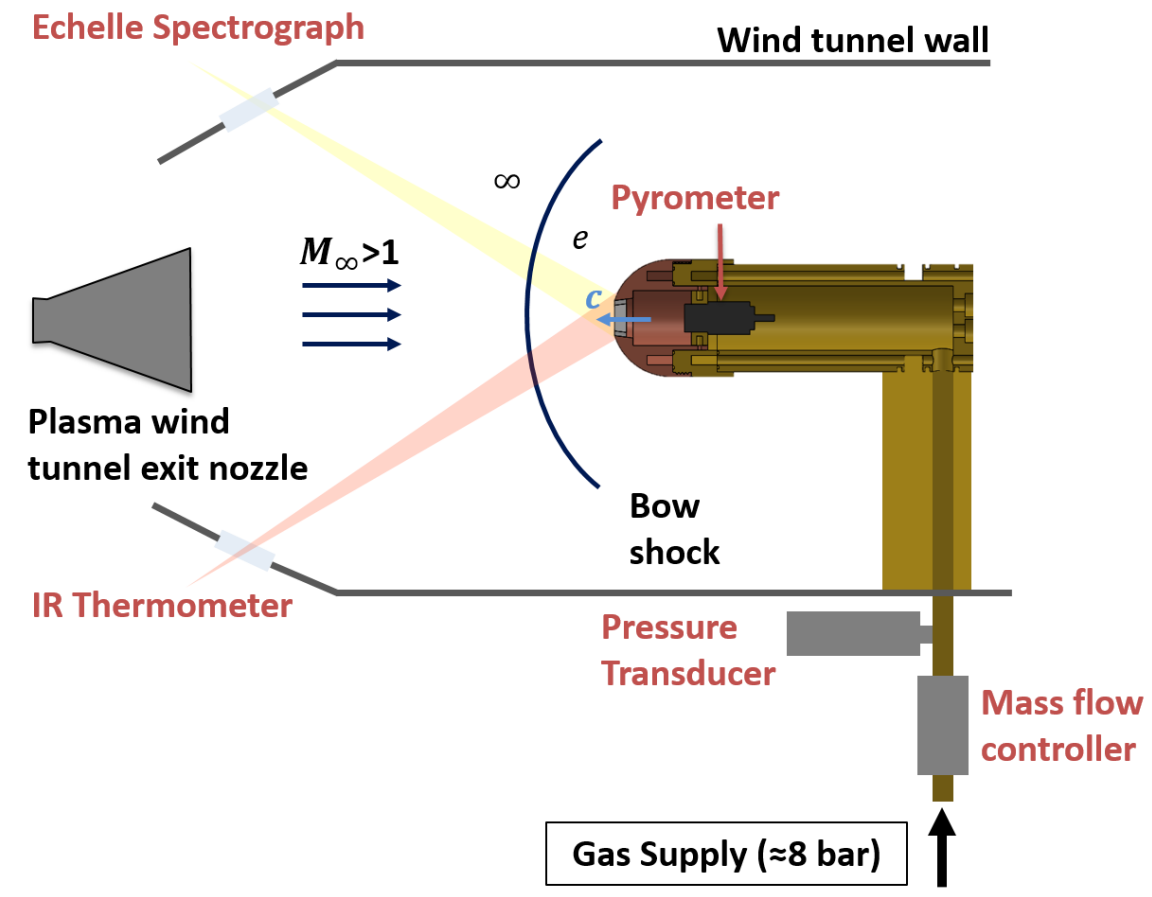

Figure 5: Sketch of experimental setup of the UHTC test in the PWK4 plasma wind tunnel.

\section{UHTC Material Properties and Through-flow Characteristics}

Porous $\mathrm{ZrB}_{2}$ was selected as UHTC material for its high melting point (3519 K) and good high temperature strength. A relatively high thermal conductivity ${ }^{18}$ of $48 \mathrm{~W} /(\mathrm{mK})$ aids the cooling through internal conduction by distributing the heat evenly. Note that the thermal conductivity scales with porosity and is $28 \mathrm{~W} /(\mathrm{mK})$ for the $42 \%$ porous sample. The $\mathrm{ZrB}_{2}$ disks $(\varnothing 80 \mathrm{~mm}$ x $5 \mathrm{~mm}$ ) were produced by hot pressing Grade-B $\mathrm{ZrB}_{2}$ powder from H.C. Starck at $1750^{\circ} \mathrm{C}$ for $1 \mathrm{~h}$ under $35 \mathrm{MPa}$ in a graphite hot press, whereas the solid, $100 \%$ dense $\mathrm{ZrB}_{2}$ was produced by hot pressing a mixture of the same powder, a phenolic resin and boron carbide at $2000^{\circ} \mathrm{C}$ also under a pressure of $35 \mathrm{MPa}$. Various samples were cut from these disks using electro-discharge machining.

The pressure drop across a porous medium is governed by the Darcy-Forchheimer equation given as

$$
-\frac{d p}{d x}=\frac{\mu}{K_{D}} v+\frac{\rho}{K_{F}} v^{2}
$$

The former term on the right-hand-side of Eq. (2) stands for viscous losses, whereas the latter term denotes the kinetic losses, which become dominant only at higher coolant velocities.

The permeability characteristics of the tested sample were determined using a permeability test rig built according to $I S O-4022^{19}$ at the Oxford Thermofluids Institute, where the pressure differential across the 
sample is recorded for increasing mass flow rates at room temperature. ${ }^{4}$ An integrated version of Eq. (2),

$$
\frac{p_{\text {in }}^{2}-p_{\text {out }}^{2}}{2 p_{\text {in }} L}=\frac{\mu\left(T_{\text {in }}\right)}{K_{D}} v_{\text {in }}+\frac{\rho\left(p_{\text {in }}, T_{i n}\right)}{K_{F}} v_{\text {in }}^{2},
$$

is employed here, which is valid for a constant fluid temperature over the thickness of the sample. Further details on the calculation can be found in Ref. ${ }^{4}$

The permeability test results are plotted in Fig. 6 and the obtained permeability coefficients are given in Table 2. It can be seen that the experimental data follow the Darcy-Forchheimer equation and the curve thereof (solid line) is well within the uncertainty-bounds. Further, it can be observed that the flow enters the Forchheimer regime at higher velocities and deviates from the projected Darcy equation (dashed line), as the kinetic losses increase.

Table 2: Permeability coefficients with their corresponding uncertainties of the tested samples. ${ }^{4}$

\begin{tabular}{llll}
\hline \hline Coefficient & Value, $X$ & Uncertainties, $\delta X$ & $\frac{\delta X}{X}$ \\
\hline \multicolumn{4}{c}{ UHTC-2 (Probe \#2) } \\
\hline$K_{D}, \mathrm{~m}^{2}$ & $2.1494 \times 10^{-14}$ & $\pm 0.0385 \times 10^{-14}$ & $1.79 \%$ \\
$K_{F}, \mathrm{~m}$ & $1.003 \times 10^{-7}$ & $\pm 0.262 \times 10^{-7}$ & $26.08 \%$ \\
\hline \multicolumn{4}{c}{$\mathrm{UHTC}-5($ Probe $\# 5)$} \\
\hline$K_{D}, \mathrm{~m}^{2}$ & $2.956 \times 10^{-14}$ & $\pm 0.064 \times 10^{-14}$ & $2.17 \%$ \\
$K_{F}, \mathrm{~m}$ & $1.105 \times 10^{-7}$ & $\pm 0.292 \times 10^{-7}$ & $26.43 \%$ \\
\hline \hline
\end{tabular}
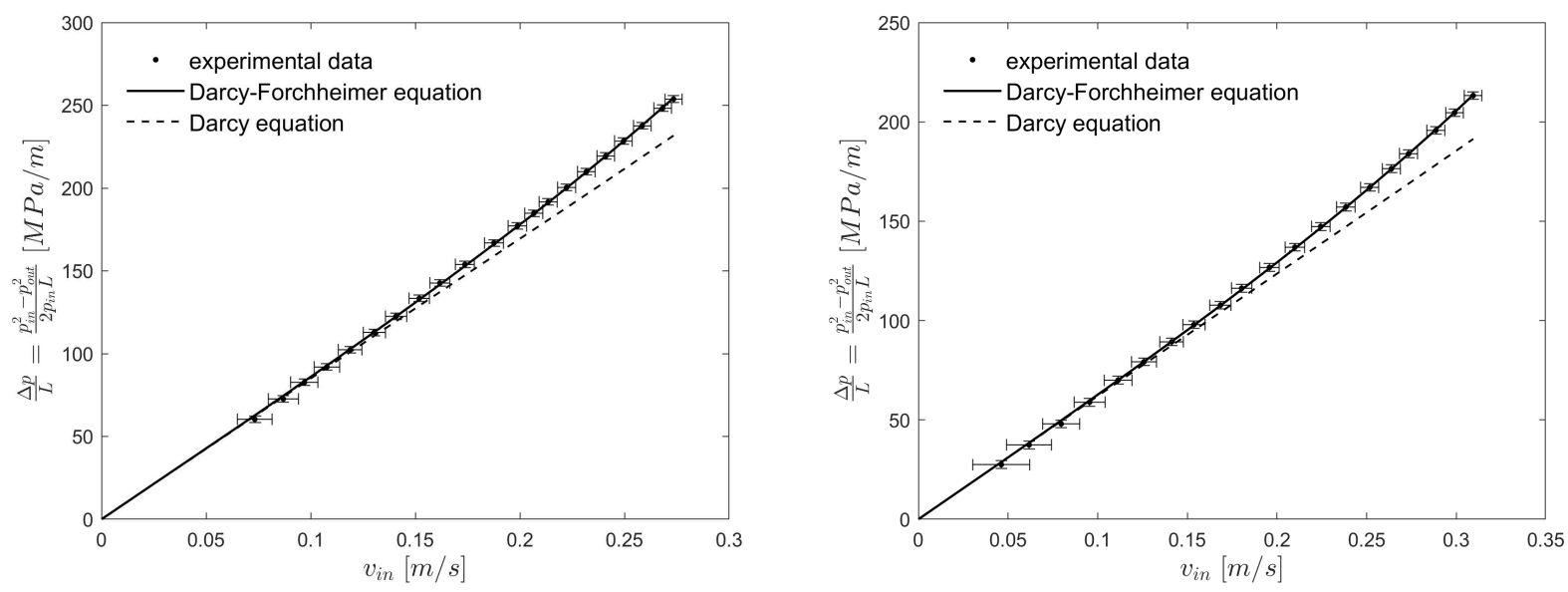

Figure 6: Experimental results of the through flow characteristics of the porous UHTC-2 (left) and UHTC-5 (right) samples and comparison to the fitted Darcy-Forchheimer equation.

\section{Experimental Results}

Three different experiments were conducted. A fully dense sample without any blowing was tested to assess the oxidation characteristics in a completely uncooled case. In addition, two samples were tested which were cooled by nitrogen and helium respectively. An overview of the tests performed is given in Table 3. Note that the blowing ratio $\mathrm{F}$ is defined as the ratio of coolant mass flux to the mass flux of the post-shock gas at the boundary layer edge:

$$
F=\frac{\rho_{c} v_{c}}{\rho_{e} v_{e}},
$$

while the blowing parameter is denoted as the blowing ratio normalised by the Stanton number of the uncooled case: ${ }^{20}$ 


$$
B_{h}=\frac{F}{S t_{0}}
$$

where

$$
S t_{0}=\frac{\dot{q}_{0}}{\rho_{e} v_{e}\left(h_{e}-h_{w}\right)} .
$$

A correlation factor is introduced, if the heat capacities of the coolant and the freestream are very different, which is the case for transpiration cooled probes exposed to the plasma freestream at condition 3. For laminar flow, the blowing parameter is multiplied by the following correlation factor: ${ }^{20}$

$$
\left(\frac{c_{p, c}}{c_{p, e}}\right)^{1 / 3}
$$

Table 3: Summary of steady state experiments

\begin{tabular}{lccccccc}
\hline \hline Condition & Probe & Gas & Time in stream & $T_{\text {front }}$ & $T_{\text {back }}$ & $\mathrm{F}$ & $B_{h}\left(\frac{c_{p, c}}{c_{p, e}}\right)^{1 / 3}$ \\
\hline 1 & & & {$[\mathrm{~s}]$} & {$[\mathrm{K}]$} & {$[\mathrm{K}]$} & & \\
2 & $\# 4$ (Solid) & None & 305.2 & 1400 & 1313 & - & - \\
3 & $\# 4$ (Solid) & None & 132.9 & 1600 & 1492 & - & - \\
3 & $\# 4$ (Solid) & None & 81.4 & 2150 & 1980 & - & - \\
3 & $\# 2$ (UHTC-2) & Helium & 75 & 1428 & 1233 & 0.0080 & 0.1094 \\
\hline \hline
\end{tabular}

Figure 7 shows pictures of the probe heads post-testing. Probe \# 5 was cooled by $620.11 \mathrm{~g} / \mathrm{m}^{2} \mathrm{~s}$ of nitrogen and heated up to a front surface temperature of $1128 \mathrm{~K}$. Despite being in a temperature regime in which oxidation is expected, it did not oxidise and only a dark grey discoloration was observed. The uncooled sample did oxidise when it was exposed to the same tunnel conditions. It reached a maximum surface temperature of $2150 \mathrm{~K}$ and was covered in a white oxide layer post-test. When probe \#2 was transpiration cooled by $20.25 \mathrm{~g} / \mathrm{m}^{2} \mathrm{~s}$ of helium it heated up to $1428 \mathrm{~K}$ and did not oxidise. However, the insulation ring cracked when the mass flux was lowered and the flow leaked through said cracks instead of transpiring the sample. With the loss of the protective coolant film, the sample surface started to oxidise.
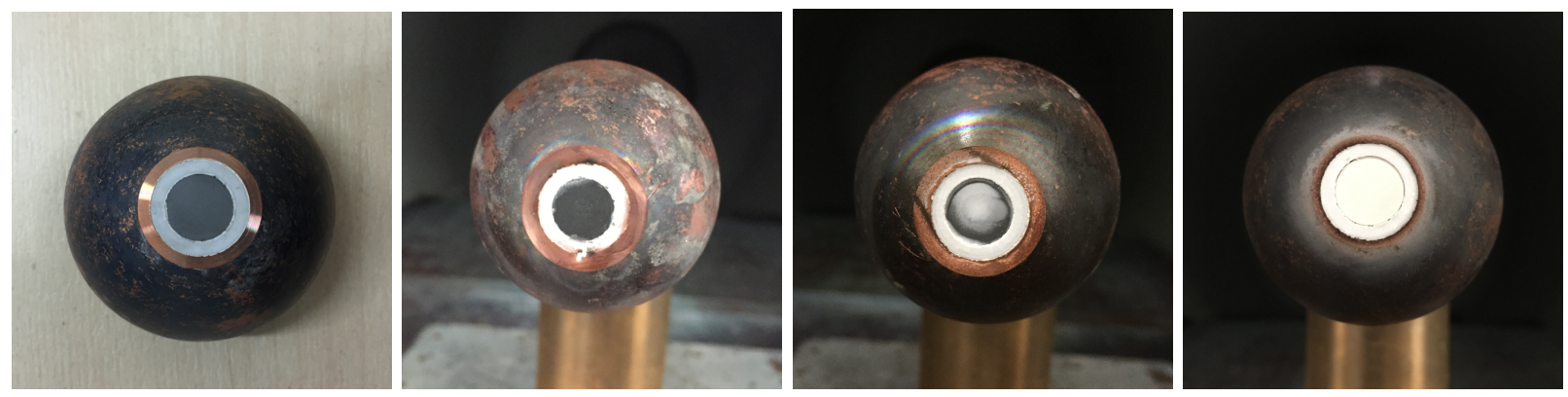

Figure 7: Untested virgin sample (left), post-test nitrogen cooled sample (center left), post-test helium cooled sample (center right) and post-test uncooled sample (right).

\section{A. Effect of Blowing Parameter on Surface Temperature.}

This section presents the calculation of the transient blowing parameter for the helium cooled test. This is done to assess the effectiveness of transpiration cooling for different gases at high enthalpy conditions. The blowing parameter, as defined in Eq. (5), is only a function of the coolant mass flux for a quasi steady state wind tunnel condition, in which the uncooled Stanton number and the boundary layer edge mass flux are constant. Hence, only the coolant mass flux must be obtained at each time step to calculate the transient blowing parameter. 
This is achieved by solving the Darcy-Forchheimer equation (Eq. (2)) for a given fluid temperature and plenum pressure. It is assumed that the fluid temperature varies linearly from room temperature at the backside to the solid wall temperature on the front surface. The measured plenum pressure is fed into the equation at each time step. Hence, all variables in Eq. (5) are known and the blowing parameter can be calculated. More details on the Darcy-Forchheimer solution that is used in this calculation can be obtained in Ref. ${ }^{21}$ The boundary layer edge mass flow rate is assumed to be equal to the free stream mass flow rate provided in Table 1. The diameter of the bright plasma stream in Fig. 3 was estimated to be similar to the diameter of the probe. The mass flow rate was hence divided by the cross-sectional area of the probe, which had a radius of $r=25 \mathrm{~mm}$, to obtain the boundary layer edge mass flux.

Figure 8 compares the blowing parameter to the surface temperatures and plenum pressure for the helium cooled case. The coolant mass flux is driven by the pressure drop across the sample and is hence dependent on the reservoir pressure. If the plenum pressure rises, the mass flux and blowing parameter will increase. However, the pressure drop is not the only variable in the equation governing the mass flux across the sample. For a constant pressure differential, less fluid will transpire the sample if the fluid temperature and hence the fluid viscosity are higher. This can be seen in Fig. 8, where the blowing parameter drops at $t=17 \mathrm{~s}$, despite a constant pressure differential, due to the rise in surface temperatures - and consequently fluid temperature. Less blowing entails less cooling, which in turn increases the surface temperature. It is hence critical to ensure that the coolant mass flux can be maintained at high surface temperatures. This can be achieved by either increasing the permeability of the porous medium or by increasing the maximum allowable supply pressure, such that the dangerous spiral of a blowing reduction due to a temperature increase can be counteracted.

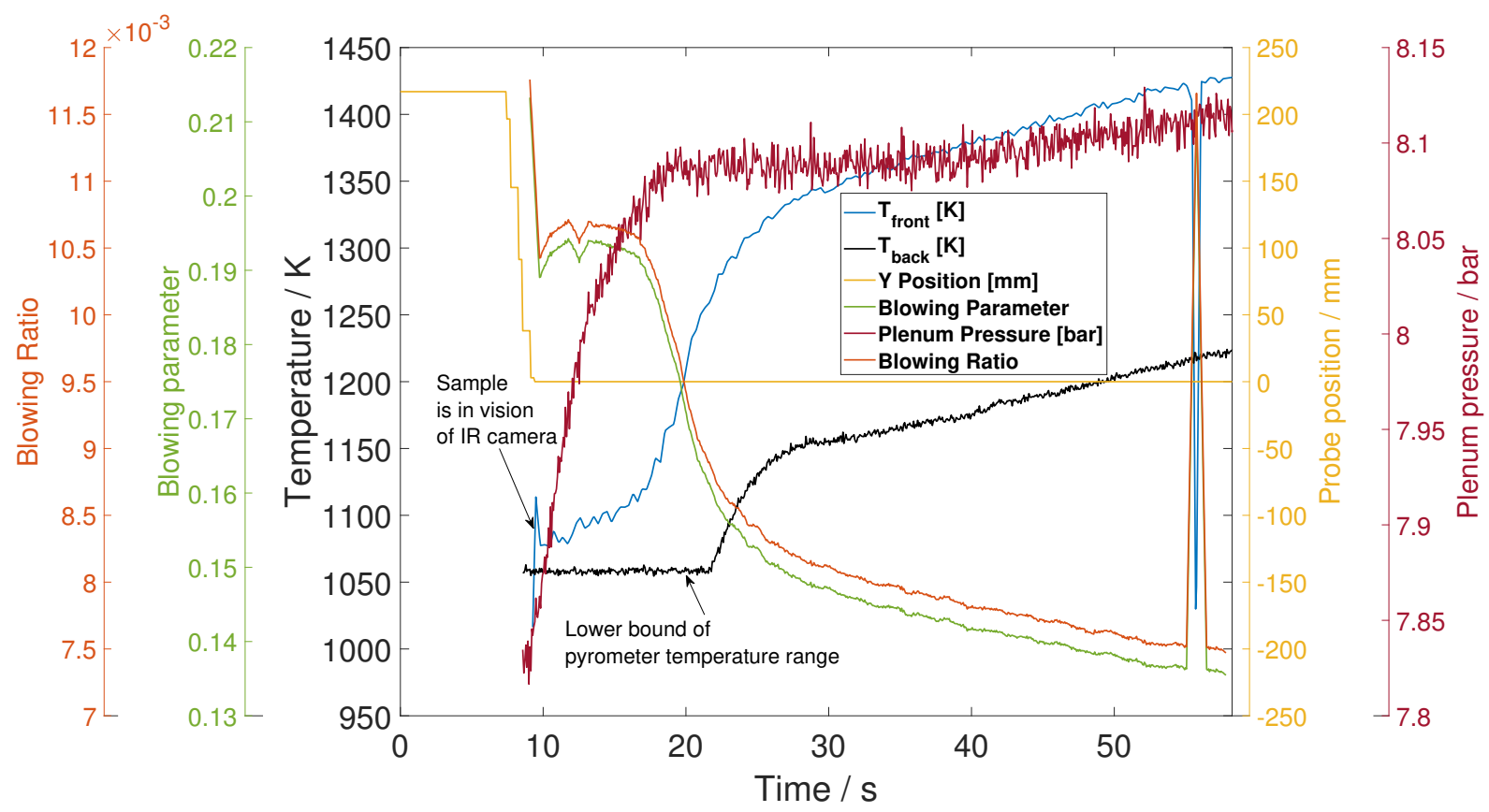

Figure 8: Interaction of blowing parameter, blowing ratio, surface temperatures and plenum pressure in the helium cooled case.

\section{B. Incident Heat Flux Reduction of Transpiration Cooled Samples}

In quasi steady state conditions, the incident heat flux on the samples must equal to the heat flux out of the sample, namely, the heat flux due to the internal convective cooling and the radiative heat flux on both surfaces (Eq. (8)). The sample surface temperatures are taken from Table 3 and the results for both samples are summarised in Table 4. The internal convective heat flux is equal to the steady-state solid-fluid heat exchange term in the energy equation of a fluid transpiring a porous medium (Eq. (9)).

$$
\dot{q}_{\text {rad }}=\sigma \varepsilon_{s}\left(T_{\text {front }}^{4}+T_{\text {back }}^{4}\right)
$$




$$
\begin{gathered}
0=\underbrace{\phi \rho_{c} c_{p, c} \frac{v_{c}}{\phi} \frac{\partial T_{c}}{\partial x}}_{\text {Convection }}+\underbrace{h_{v}\left(T_{s}-T_{c}\right)}_{\text {Solid-fluid heat exchange }} \\
\partial T_{c}=-\frac{1}{\rho_{c} v_{c} c_{p, c}} h_{v}\left(T_{s}-T_{c}\right) \partial x
\end{gathered}
$$

The solid temperature is known on both surfaces and is assumed to vary exponentially from the back surface to the front surface of the sample. To find the steady-state values, the equation is rearranged as shown in Eq. (10). The coolant mass flux is still unknown, but correlates with the pressure drop across the sample. Hence, a mass flux is assumed to solve Eq. (10) and obtain the fluid temperature across the sample. Afterwards, the pressure drop between the back and front surface is computed based on these fluid temperature values, by rearranging and discretising the Darcy-Forchheimer differential equation (Eq. (2)) in Eq. (11).

$$
p_{x}=p_{x-1}-\left(\frac{\mu_{c}\left(T_{c}\right)}{K_{D}} v+\frac{\rho_{c}\left(T_{c}, p_{c}\right)}{K_{F}} v^{2}\right) \Delta x,
$$

In an iterative process, the mass flux is adjusted until the pressure drop across the sample matches the boundary conditions, namely the measured plenum pressure at the back surface and the stagnation pressure at the front surface. The viscosity in Eq. (11) is calculated based on Sutherland's law. The density of the coolant is evaluated from the ideal gas equation and the velocity is found from continuity. Finally, the Shomate equation with the coefficients provided by Chase ${ }^{22}$ is used to find the heat capacity of the fluid at every spatial iteration. The through-flow area is known and used to convert between mass flux and mass flow rate. It was deduced from a velocity map, which was obtained before the plasma wind tunnel test. A hot wire hovered about $2 \mathrm{~mm}$ above the $\mathrm{ZrB}_{2}$ sample and recorded the exit velocity of the coolant flow with a $1 \mathrm{~mm}$ x $1 \mathrm{~mm}$ pixel resolution. For both samples the through-flow area was approximately circular with a diameter of $9 \mathrm{~mm}$.

Once the cooling temperature is determined, the term denoting the solid-fluid heat exchange in Eq. (9) is computed at every step. It represents the heat flux absorbed by the fluid phase at a spatial location $\mathrm{x}$ and is integrated throughout the sample depth to obtain the total internal convective heat flux of the sample. Normalisation is needed to compare the data obtained at different wind tunnel conditions. It is performed by either the nominal heat flux, provided by the fully catalytic, oxidised copper heat flux probe or by the heat flux obtained from heat flux equilibrium of the uncooled $\mathrm{ZrB}_{2}$ probe. The former is obtained by multiplying the cold wall heat flux from Table 1 with a correction factor to account for the difference in wall temperatures between the water cooled heat flux probe and the the uncooled $\mathrm{ZrB}_{2}$ probe. This is done as follows:

$$
\dot{q}_{0, \text { nom }}=\dot{q}_{0, \text { cold }} \frac{h_{e}-h_{w}}{h_{e}-h_{\text {cold }}} .
$$

$\dot{q}_{0, \text { uncooled }}$ is equal to the radiative heat flux of the uncooled sample and calculated with Eq. (8) based on the temperature values of Table 3 . A summary of the heat fluxes is provided in Table 4 . Table 5 summarises the values used in this calculation.

Table 4: Heat Fluxes of Tested Sample.

\begin{tabular}{cccccc}
\hline \hline Probe & $\dot{q}_{\text {rad }}$ & $\dot{q}_{\text {conv }}$ & $\dot{q}_{\text {reduced }}$ & $\dot{q}_{0, \text { nom,tc3 }}$ & $\dot{q}_{\text {0,uncooled,tc3 }}$ \\
\hline & {$\left[M W / m^{2}\right]$} & {$\left[M W / m^{2}\right]$} & {$\left[M W / m^{2}\right]$} & {$\left[M W / m^{2}\right]$} & {$\left[M W / m^{2}\right]$} \\
\hline$\# 2$ & 0.2655 & 0.0911 & 0.3566 & 3.59 & 1.55 \\
$\# 5$ & 0.108 & 0.1505 & 0.2585 & 3.59 & 1.55 \\
\hline \hline
\end{tabular}

The transient heat flux reduction values for different mass fluxes of coolant gas are provided by Ref. ${ }^{10}$ They formed part of the NISIp calibration method and were obtained while the probe was exposed to a free stream at condition 4 . The values are already normalised by $\dot{q}_{0, \text { nom,tc } 4}=2 \mathrm{MW} / \mathrm{m}^{2}$. During these transient exposures, the sample surface did not exceed $550 \mathrm{~K}$. Hence $h_{w}$ is negligible and there is no need for a correction (Eq. (12)). The heat flux based off the heat flux equilibrium value of the solid sample 
Table 5: Coolant Properties and Geometric Parameters of Tested Samples.

\begin{tabular}{lccccccc}
\hline \hline Probe & Coolant & $p_{\text {plenum }}$ & $\dot{m}$ & $\mathrm{~L}$ & $\mathrm{~A}$ & $\mathrm{R}$ & $c_{p, c}$ \\
\hline & & {$[\mathrm{bar}]$} & {$[\mathrm{mg} / \mathrm{s}]$} & {$[\mathrm{mm}]$} & {$\left[\mathrm{mm}^{2}\right]$} & {$\left[\mathrm{Jkg}^{-1} \mathrm{~K}^{-1}\right]$} & {$\left[\mathrm{Jkg}^{-1} \mathrm{~K}^{-1}\right]$} \\
\hline$\# 2$ & Helium & 8.10 & 1.288 & 4.63 & 63.617 & 2077.1 & 5193 \\
$\# 5$ & Nitrogen & 7.87 & 39.45 & 5.11 & 63.617 & 296.80 & 1061 \\
\hline \hline
\end{tabular}

exposed to condition 4 is given as $\dot{q}_{0 \text {, uncooled,tc } 4}=0.2898 \mathrm{MW} / \mathrm{m}^{2}$. The analytic solution provided by Kays $\&$ Crawford $^{20}$ is used for comparison (Eq. 13).

$$
\frac{\dot{q}}{\dot{q}_{0}}=\frac{B_{h}}{e^{B_{h}}-1}
$$

Now that the heat flux reduction $\frac{\dot{q}}{\dot{q}_{0}}$ is known, it remains to find the corresponding blowing parameters. They are calculated by multiplying Eq. (5) by the correction factor (Eq. (7)):

$$
B_{h}\left(\frac{c_{p, c}}{c_{p, e}}\right)^{1 / 3}=\frac{F c_{p, e} \rho_{e} v_{e}\left(T_{e}-T_{w}\right)}{\dot{q}_{0}}\left(\frac{c_{p, c}}{c_{p, e}}\right)^{1 / 3}=\frac{\rho_{c} v_{c}\left(h_{e}-h_{w}\right)}{\dot{q}_{0}}\left(\frac{c_{p, c}}{c_{p, e}}\right)^{1 / 3}
$$

The mass fluxes for the steady state and the transient tests are known, as well as the difference in enthalpies, which can be deduced from Table 1 . The heat capacities are given in Table 1 and 5 .

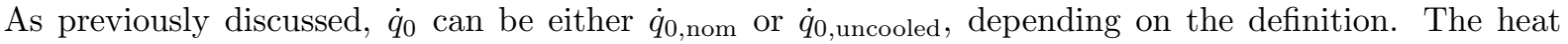
capacity of the coolant exiting the porous medium is again computed from the Shomate equations based on the coefficients provided by Chase $^{22}$ and the fluid temperature at the wall, previously computed by solving Eq. (9). The equilibrium heat capacity of the post-shock gas at the boundary layer edge, $c_{p, e}$ was evaluated in a tp type problem using CEA, ${ }^{14}$ with pressure and temperature taken from Table 1.

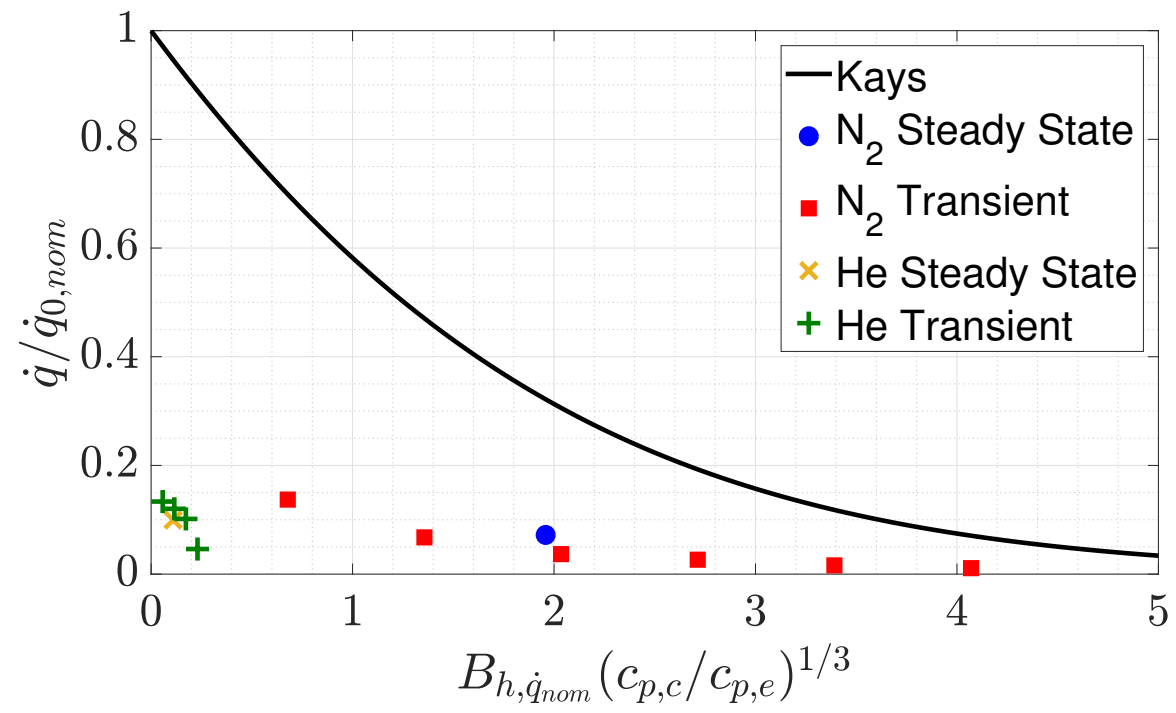

Figure 9: Heat flux reduction due to blowing, normalised by the nominal heat flux.

The results, once normalised by $\dot{q}_{0, \text { nom }}$ and then by $\dot{q}_{0, \text { uncooled }}$ are plotted in Fig. 9 and 10 . It is apparent that the experimental results show a much stronger cooling than predicted by theory for the nominal normalisation. At this point it should be noted that the analytical solution provided by Kays \& Crawford $^{20}$ does not take into account real gas effects, of which there are many in high-enthalpy flows. Clearly, the uncooled sample experienced a strong, exothermic, surface oxidation, possibly also nitration. In addition, there are many other activated species in the post-shock plasma flow that could have recombined at the surface and lead to even more catalytic heating. It is unclear, how much of the total heat flux can be linked to these catalytic effects. 
However, the steep drop in incident heat flux even at low blowing parameters, suggests that the smallest amounts of the ejected fluid create a barrier that mitigates the diffusion of activated species through to the surface, which drastically reduces the incident heat flux. This extreme reduction in heat flux with the smallest amount of blowing has previously been observed and studied in Ref. ${ }^{23}$ As the temperature of the post-shock gas rises, the relative amount of dissociated, ionised and activated species increases as well, which suggests that the share of catalytic heat flux of the total heat flux grows. The drop in heat flux for the helium cooled sample in condition 3 is much deeper than in condition 4, perhaps precisely because the share of catalytic heat flux is much higher and is removed with the slightest blowing. However, the heat reduction of nitrogen in condition 3 is worse than that of nitrogen in condition 4 . This seems to suggest that the better normalisation factor is the heat flux incident on the uncooled $\mathrm{ZrB}_{2}$ sample. In fact, since the catalytic effects are extremely dependent on the surface material composition, ${ }^{24}$ it is sensible to use a normalising heat flux obtained by the same probe geometry and material characteristics. If the heat flux incident on the uncooled sample is chosen, the heat flux reduction of the probes exposed to condition 3 is larger for both samples compared to the transient cases.

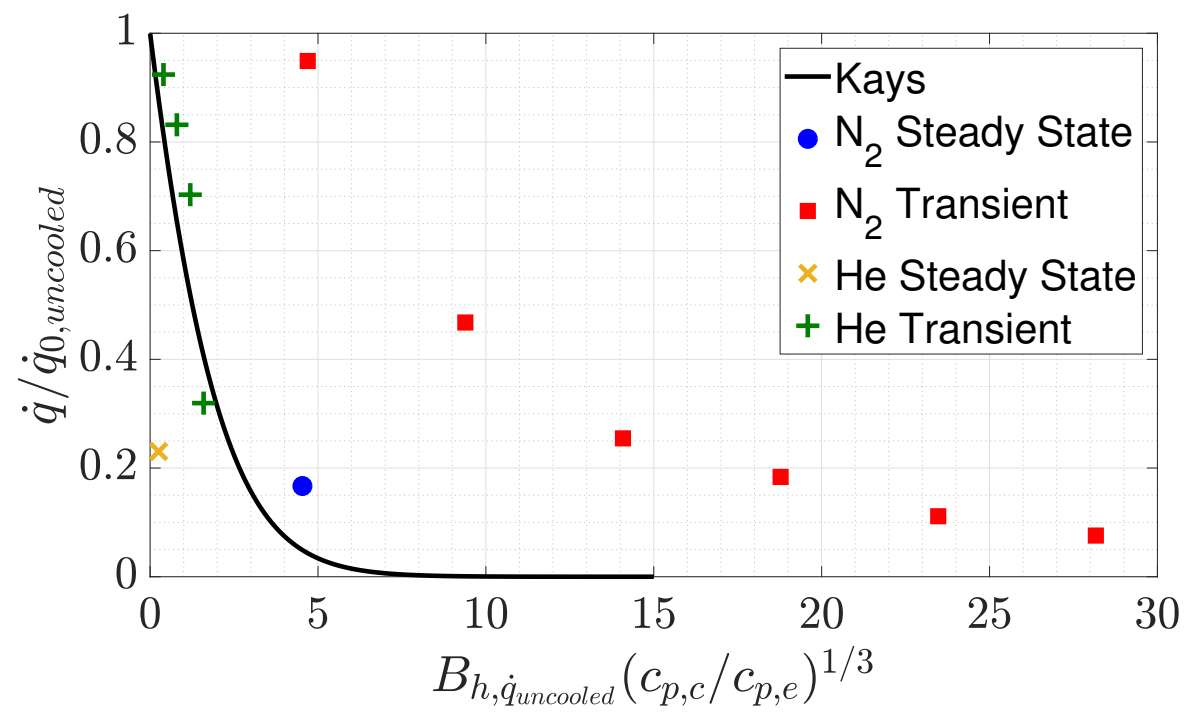

Figure 10: Heat flux reduction due to blowing, normalised by the incident heat flux on the uncooled sample.

Despite the multiplication of the correlation factor, there is a discrepancy in cooling performance between the two gases, with Helium being the better coolant by a margin. To the author's knowledge it has not been specified in literature whether the correlation factor should contain the equilibrium or the frozen heat capacity of the post-shock gas. As the flow moves through the nozzle, the electrical energy will gradually be transferred into internal energy and finally into kinetic energy when it leaves the nozzle and crosses the bow shock. The equilibrium values have been chosen for these calculations. A second unknown and possible source of discrepancy in the results is the Reynolds number of the transpiration cooled stagnation point. If the flow was turbulent, the exponent of the correlation factor would be 0.6 instead of $1 / 3$. The low pressure and high temperature suggest that the Reynolds number is very low and the flow hence laminar. However, the high-frequency, transient oscillations of the arc-generator could break up the laminar structures. It is also unclear to which extent the Reynolds number is affected by the blowing. Since both of the latter effects would need further investigation to be confirmed, the flow was assumed to be laminar in this case.

\section{Extracting Front Surface Temperature and Emissivity from the Spectra}

In this section, emission spectra of the Echelle spectrograph measurements are analysed. The spectra contain the plasma line emission and the black body radiation of the sample surface. The spectral distribution of electromagnetic radiation emitted by a grey body is described by Planck's law:

$$
B_{\lambda}\left(\lambda, T, \varepsilon_{s}\right)=\frac{2 h c^{2}}{\lambda^{5}} \frac{1}{e^{\frac{h c}{\lambda k_{B} T}}-1} \varepsilon_{s} .
$$


The front surface temperature of an object can be obtained by fitting Eq. (15) to the recorded spectra, as illustrated in Fig. 11

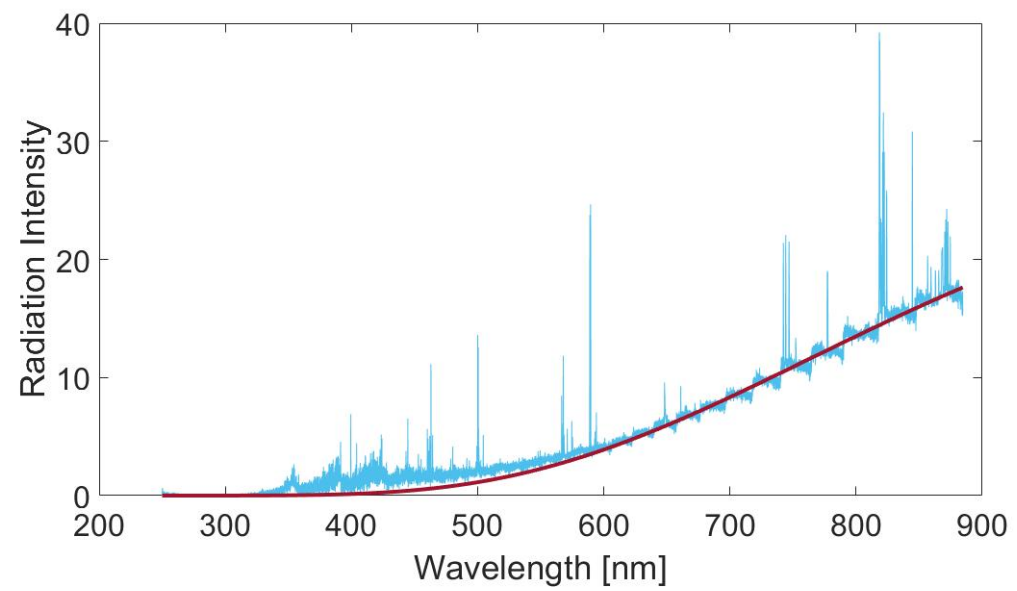

Figure 11: The front surface temperature is obtained by fitting the Planck curve to the spectrum.

Not all of the radiation the Echelle spectrometer records is blackbody radiation. The lines and bands, especially at small wavelengths are emitted by specific atoms or molecules. The spectral band of $N_{2}^{+}$can clearly be seen at around $400 \mathrm{~nm}$, which is why the curve fit is only performed in the relatively clean interval from $600-900 \mathrm{~nm}$.

The result for the uncooled probe (probe \#4) at condition 3 is plotted in Fig. 12 and compared to the temperature values obtained by the infrared camera. The discrepancy in the measurements could be due the changing surface emissivity of oxidising $\mathrm{ZrB}_{2}$. Temperature is purely a function of curvature in the Planck fit, while the IR camera necessitates an emissivity value to convert the detected irradiance to a temperature value. While $\mathrm{ZrB}_{2}$ has an emissivity of $\varepsilon_{s}=0.75$ at room temperature, ${ }^{16}$ the emissivity might have changed at elevated temperatures and after surface oxidation. Both temperature measurements match for an emissivity of $\varepsilon_{s}=0.562$.

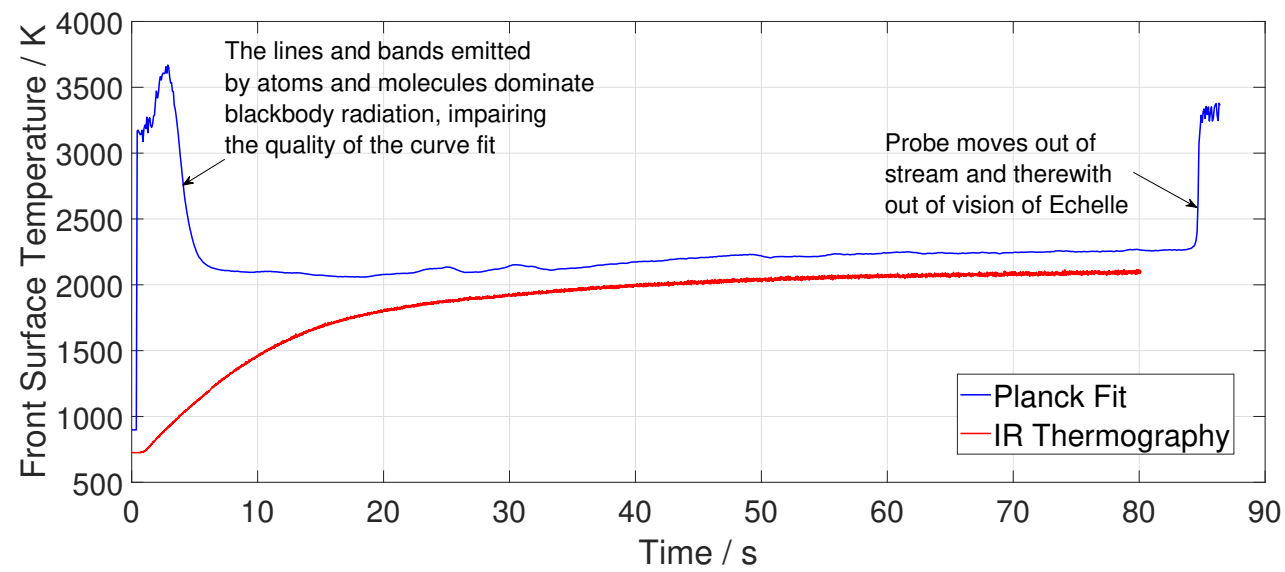

Figure 12: Surface temperature obtained through Planck curve fit vs surface temperature measured by IR thermography camera assuming $\varepsilon_{s}=0.75$.

\section{Qualitative Assessment of Spectra}

Figure 13 shows a comparison between the emission spectra in front of the sample in the cases of the solid sample and the helium cooled sample. Figure 14 shows the comparison between an uncooled sample and a nitrogen cooled sample. The spectra of the solid sample was taken $17 \mathrm{~s}$ after it was moved into the stream, 
while the helium and nitrogen spectra were obtained after $11 \mathrm{~s}$ and $4 \mathrm{~s}$ in the stream, respectively. The expected air plasma lines $\left(\mathrm{N}_{2}^{+}, \mathrm{N}, \mathrm{O}\right)$ and bands are observed which are naturally present at these high enthalpy conditions. In addition, many foreign species can be identified that stem from the interaction of the plasma with the sample. The oxidation and ablation of the surface leads to a diffusion of various material sample species into the hot stagnation point plasma. The inner degrees of freedom of those particles are then excited and the the characteristic radiative transitions can be observed by the Echelle spectrometer. As expected, $\mathrm{Zr}$ lines are visible which show that the surface is recessing over time and the material is slowly eroded. Furthermore, species originating from the insulating high temperature glue are present in the boundary layer $(\mathrm{C}, \mathrm{Si}, \mathrm{Mg})$ as well as common impurities like Na.

Except for the massive difference in background radiation level, only very little difference in line radiation is noticed between a cooled case and an uncooled case. Additional lines of $\mathrm{Zr}, \mathrm{Si}$ and $\mathrm{C}$ are visible as well as the Balmer alpha line of $\mathrm{H}$. Only two notable differences between the two coooled cases are observed. In the case of nitrogen blowing, the Na lines at $598 \mathrm{~nm}$ are completely suppressed. For helium cooling two additional lines at $766.4 \mathrm{~nm}$ and $769.9 \mathrm{~nm}$ appear that are characteristic of $\mathrm{K}$.

As will be shown in section E, many of these species can be retraced to different points of origin of the probe design, such as the porous sample itself, the high temperature glue or the coolant.

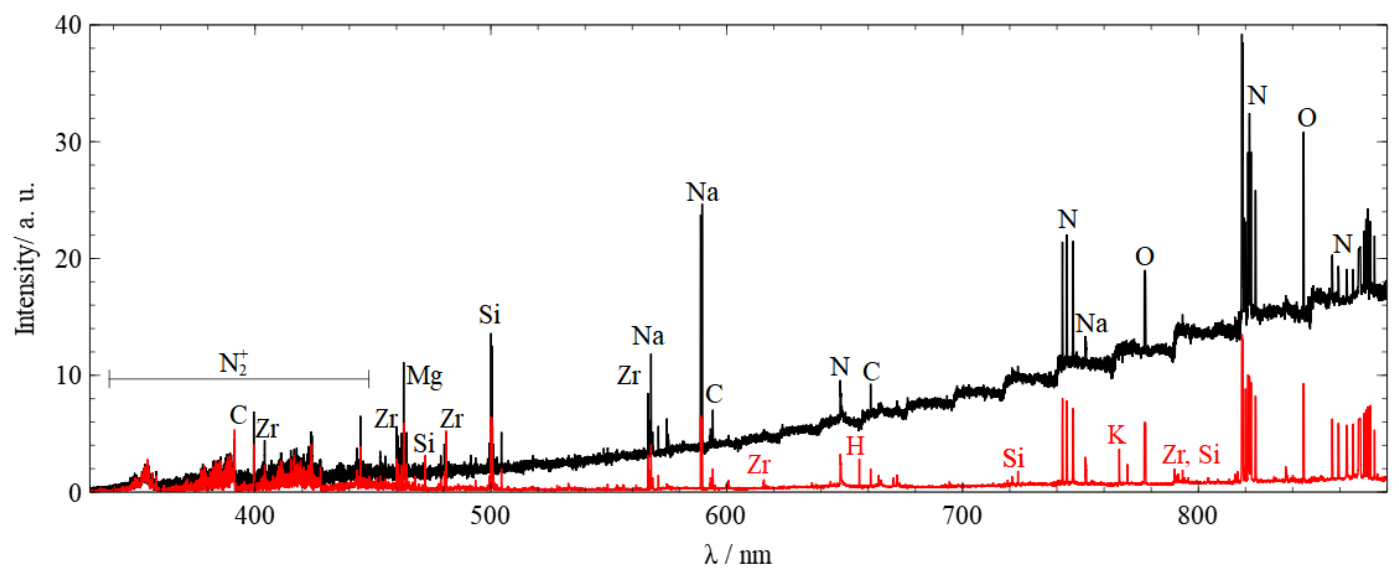

Figure 13: Spectra of solid sample (black) and helium cooled sample (red).

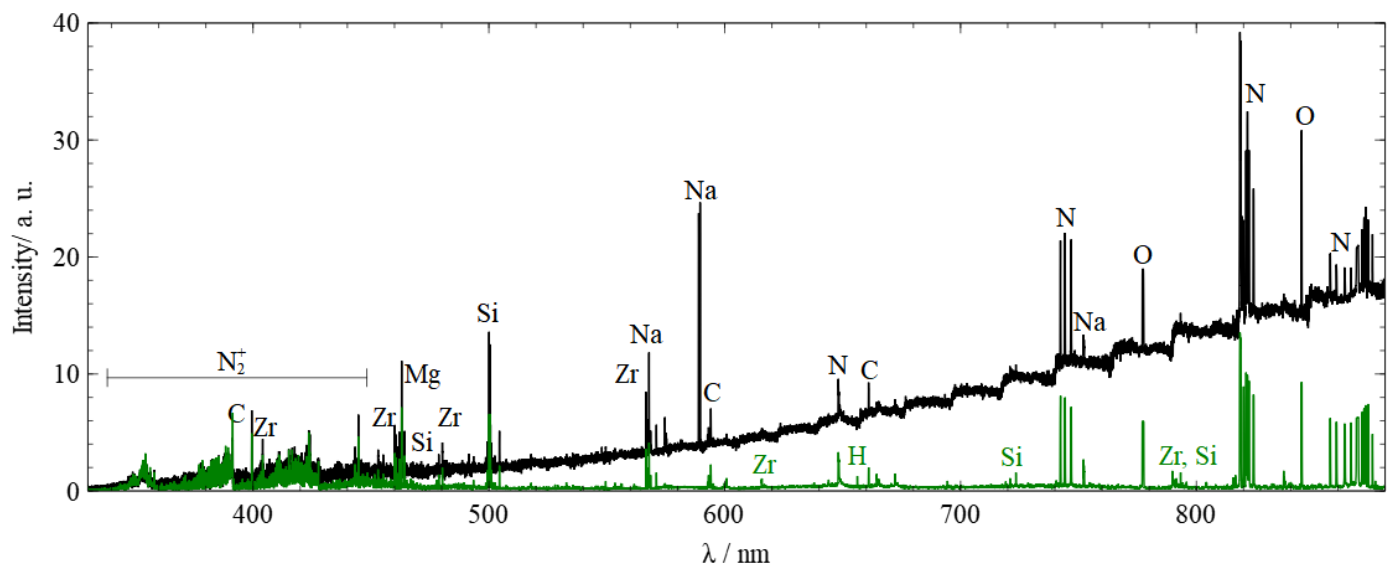

Figure 14: Spectra of solid sample (black) and nitrogen cooled sample (green). 


\section{E. Post-test Characterisation of Samples}

As the surface was observed in a SEM, radial cracks in the $\mathrm{ZrO}_{2}$ ring, as well as circumferential cracks at the interface between said ring and the $\mathrm{ZrB}_{2}$ sample were found in all three tested probes. The cracks in the insulation ring could have been caused by a thermal shock, inducing a sudden expansion. The circumferential cracks were most likely caused at high temperatures at which the glue started to erode. By sintering the $\mathrm{ZrB}_{2}$ directly into the insulation ring, these cracks could be avoided and better sealing achieved even at low blowing rates.

The surface of the dense reference sample, which was not cooled during the exposures to the plasma, became white and as shown in Fig. 15 a crust has formed on top of the sample. Elemental analysis, as well as mass spectroscopy of the crust showed it consisted of oxygen and zirconium alone and hence can be identified as $\mathrm{ZrO}_{2}$. In order to look beneath the surface and characterise the sample at different depths, the sample was cut. The cross-section confirms that an oxide layer of approximately $80 \mu \mathrm{m}$ has formed, see Fig. 16 , with a clear interface with the remaining $\mathrm{ZrO}_{2}$ material. Consistent with the literature for oxidation of $\mathrm{ZrB}_{2}$ above $1800^{\circ} \mathrm{C},{ }^{9}$ all boron had evaporated from the oxide scale.

The surface of the helium cooled sample had partly discoloured white, but only as a result of the final exposures at lower mass flow rate. The surface morphology has changed substantially from the untested surface. Elemental analysis indicated the presence of zirconium, oxygen and some silicon. This is consistent with the species identified through spectral analysis. The silicon is believed to originate from the high temperature cement used to seal the specimens in the sample holder and which was found to be eroded substantially. The cross section together with elemental mapping indicates that the oxide layer consist essentially of a single row of grains and hence is very thin $(<5 \mu \mathrm{m})$. Below this the material is essentially unchanged from the untested microstructure apart from the fact that the pores have now been filled with the epoxy used to stabilise the microstructure before cutting.

The surface of the nitrogen cooled sample became darker during testing but showed no discoloration towards white. Fig. 15 also illustrates that this sample showed the smallest change in morphology from the untested material: the grains and pores are still clearly visible but some of the grains are now covered in small crystals, which formed during the low blowing rates. Elemental analysis showed the presence of zirconium, oxygen, boron, carbon, magnesium and silicon. The silicon and magnesium again are attributed to re-deposition of the eroded cement on the sample surface. The cross section at the surface of the sample, shown in Fig. 16, also shows very little evidence of morphological changes apart from the epoxy infiltration of the pores, suggesting almost no oxidation has occurred in this case.

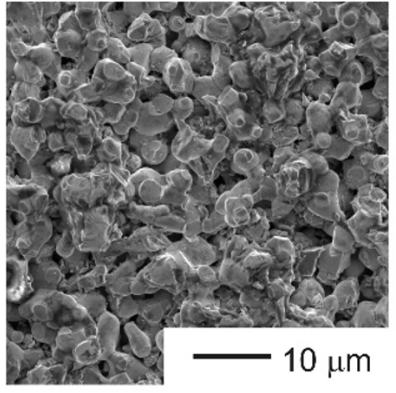

Before testing

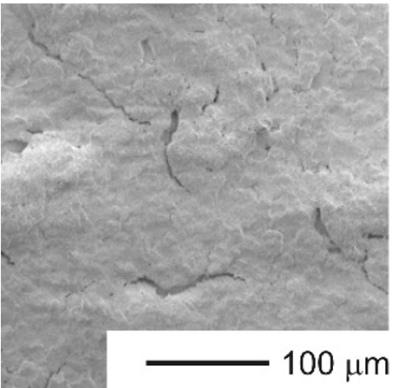

No cooling

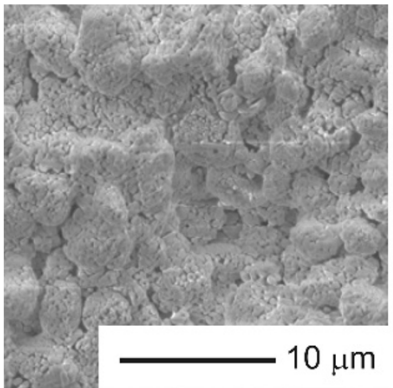

He cooled

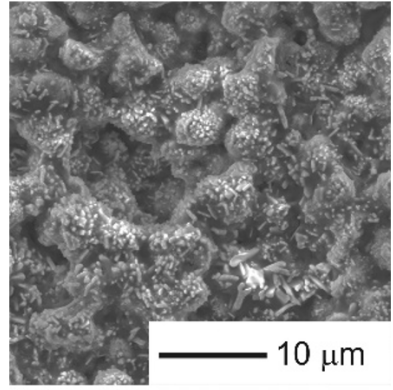

$\mathrm{N}_{2}$ cooled

Figure 15: Surface Microstructures before and after testing. 

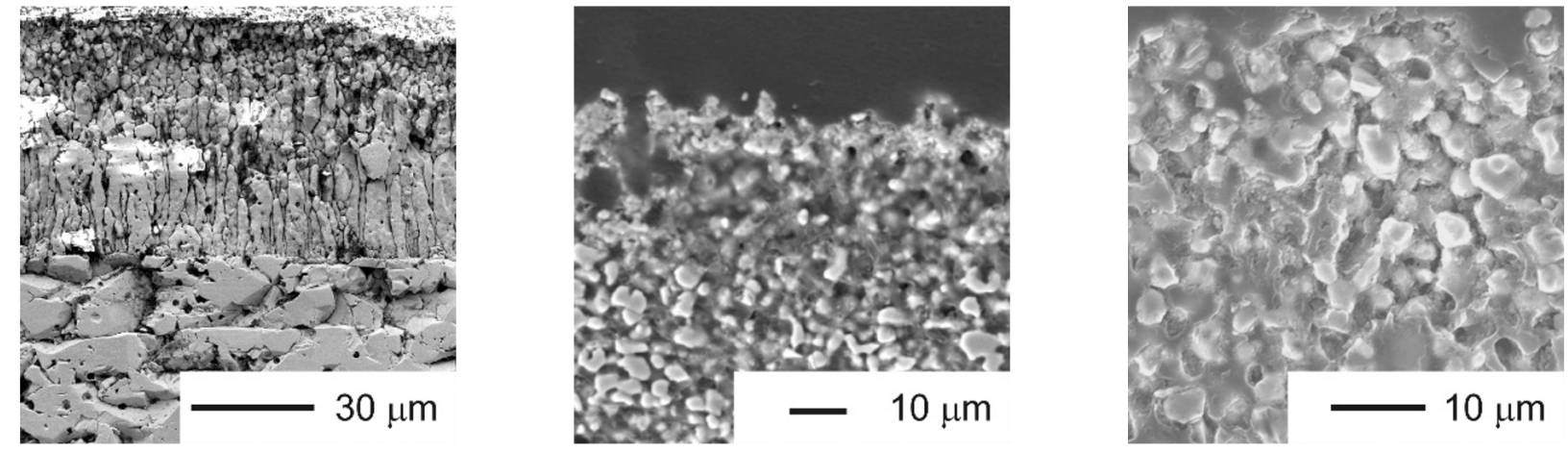

Figure 16: Cross-sections after testing for the uncooled (left), helium cooled (center) and nitrogen cooled sample (right).

\section{Conclusion}

Three stagnation probes with transpiration cooled $\mathrm{ZrB}_{2}$ samples were tested in a plasma wind tunnel. After exposure to the same flow conditions, the uncooled $\mathrm{ZrB}_{2}$ sample was covered in an $80 \mu \mathrm{m}$ oxide layer, while the nitrogen transpiration cooled counterpart showed no signs of oxidation at a coolant mass flux of $620.11 \mathrm{~g} / \mathrm{m}^{2} \mathrm{~s}$. The helium cooled sample did not oxidise at a coolant mass flux of $20.25 \mathrm{~g} / \mathrm{m}^{2} \mathrm{~s}$. The uncooled probe reached a front surface temperature of $2150 \mathrm{~K}$ at a nominal heat flux of $3.59 \mathrm{MW} / \mathrm{m}^{2}$. The helium and nitrogen cooled probes were cooled down to $1428 \mathrm{~K}$ and $1128 \mathrm{~K}$ respectively. Helium is the much better coolant for a given blowing parameter. The incident heat flux was reduced by $77 \%$ compared to the uncooled sample for a mass flow rate of $1.288 \mathrm{mg} / \mathrm{s}$. The incident heat flux on the nitrogen cooled sample was reduced by $83.3 \%$ compared to the uncooled sample for a mass flow rate of $39.45 \mathrm{mg} / \mathrm{s}$. Catalytic heat flux makes up a large percentage of the total heat flux in high-enthalpy flows and is not accounted for by the analytical prediction for heat flux reduction suggested by Kays \& Crawford. Even smallest amounts of coolant reduce the incident heat flux drastically. A Planck curve fit of the spectrum of the uncooled sample, suggests that the emissivity of the oxidised surface at $2150 \mathrm{~K}$ is $\varepsilon_{s}=0.562$. A post-test characterisation confirmed that the crust on the uncooled $\mathrm{ZrB}_{2}$ sample consists of $\mathrm{ZrO}_{2}$. Whether oxidation was prevented solely by mitigating the diffusion of oxygen through to the surface or whether it was aided by mitigating catalytic heating in general, which reduced the surface temperature down to values at which the oxidation rate is low, remains to be investigated. The next test campaign will compare probes with different blowing parameters, but constant front surface temperatures to isolate these effects.

\section{Acknowledgments}

This research is funded by the EPSRC grant "Transpiration Cooling Systems for Jet Engine Turbines and Hypersonic Flight" (reference: EP/P000878/1). The authors of this paper would like to thank Greg King, Duncan Blake and Leo Verling for their dedicated attention to detail and assistance in building the experimental rig.

\section{References}

${ }^{1} \mathrm{~T}$. A. Heppenheimer and United States. Facing the heat barrier [electronic resource] : a history of hypersonics / T.A. Heppenheimer. National Aeronautics and Space Administration, NASA History Division, Office of External Relations Washington, DC, 2007.

${ }^{2}$ G. Milgrom. Space Shuttle Thermal Protection System. Gary Milgrom, 2013.

${ }^{3}$ B.V. Coplan and R.W. King. Applying the Ablative Heat Shield to the Apollo Spacecraft. In 1967 (4th) Space Congress Proceedings, Wilmington, MA, Apr 1967.

${ }^{4}$ H.S. Ifti, T. Hermann, and M. McGilvray. Flow Characterisation of Transpiring Porous Media for Hypersonic Vehicles. In 22nd AIAA International Space Planes and Hypersonics Systems and Technologies Conference, Orlando, Florida, 2018.

${ }^{5}$ J.J. Bertin. Hypersonic Aerothermodynamics. AIAA Textbooks Series. American Institute of Aeronautics and Astronautics, 1994.

${ }^{6}$ H. Böhrk, H. Elsäßer, and H. Weihs. Flight Data from the Faceted TPS on SHEFEX II. In 8th ATD, Lisbon, 2015. 
${ }^{7}$ Narottam P. Bansal. Handbook of Ceramic Composites. Springer-Verlag New York Inc., 2010. 2005.

${ }^{8}$ William G. Fahrenholtz. The ZrB2 Volatility Diagram. Journal of the American Ceramic Society, 88(12):3509-3512,

${ }^{9}$ Triplicane Parthasarathy, R.A. Rapp, M M. Opeka, and R.J. Kerans. A model for the oxidation of ZrB2, HfB2 and TiB2. Acta Materialia, 55:5999-6010, 032007.

${ }^{10}$ Fabian Hufgard, Stefan Loehle, Jens von Wolfersdorf, Stefanos Fasoulas, Marc Ewenz Rocher, Tobias Hermann, Matthew McGilvray, and Johan Steelant. Surface Heat Flux Measurement in Transpiration Cooled Porous Materials using Plenum Pressure Data. In AIAA SciTech, San Diego, 012019.

${ }^{11}$ Monika Auweter-Kurtz and Thomas Wegmann. Overview of irs plasma wind tunnel facilities, 101999.

${ }^{12}$ Stefan Loehle, Stefanos Fasoulas, Georg Herdrich, Tobias A. Hermann, Bartomeu Massuti-Ballester, Arne Meindl, Adam S. Pagan, and Fabian Zander. The Plasma Wind Tunnels at the Institute of Space Systems: Current Status and Challenges. In 32nd AIAA Aerodynamic Measurement Technology and Ground Testing Conference, Washington, 2016.

${ }^{13}$ E V. Zoby. Empirical stagnation-point heat-transfer relation in several gas mixtures at high enthalpy levels. 111968.

${ }^{14} \mathrm{C}$ Snyder. Cearun, 2012.

${ }^{15}$ Matweb. [Online] Zirconium Oxide, Zirconia, ZrO2. Available at:

http://www.matweb.com/search/datasheet.aspx?MatGUID=0742ddaddf80467fb6532e025c694e89. [Accessed 6 Jun. 2018].

${ }^{16}$ M. Balat-Pichelin, E. Bche, D. Sciti, and D. Alfano. Emissivity, Catalycity and Microstructural Characterization of ZrB2SiCfiber based UHTC at High Temperature in a Non-equilibrium Air Plasma Flow. Ceramics International, 40(7, Part A):9731 - 9742, 2014 .

${ }^{17}$ Stefan Löhle, Sven Schweikert, and Jens von Wolfersdorf. Method for Heat Flux Determination of a Transpiration-Cooled Wall from Pressure Data. Journal of Thermophysics and Heat Transfer, 30(5), 2016.

${ }^{18}$ James W. Zimmermann, Gregory Hilmas, William Fahrenholtz, Ralph Dinwiddie, Wallace Porter, and Hsin Wang. Thermophysical Properties of ZrB2 and ZrB2SiC Ceramics. Journal of the American Ceramic Society, 91:1405 - 1411, 02 2008.

${ }^{19}$ BS EN ISO. 4022:2006, 2006.

${ }^{20}$ M. E. Kays, W.M.; Crawford. Convective Heat and Mass Transfer. McGraw-Hill, Inc., 1993.

${ }^{21} \mathrm{~J}$. Langener, T;Von Wolfersdorf. Experimental investigations on transpiration cooling for scramjet applications using different coolants. AIAA JOURNAL, 49(7), July 2011.

${ }^{22}$ Jr. Chase, M.W. NIST-JANAF Themochemical Tables. J. Phys. Chem. Ref. Data, Monograph 9(Fourth Edition):1-1951, 1998.

${ }^{23}$ Hirotaka Otsu, Kazuhisa Fujita, and Takeshi Ito. Application of the transpiration cooling method for reentry vehicles. Collection of Technical Papers - 45th AIAA Aerospace Sciences Meeting, 21, 012007.

${ }^{24}$ Stefan Loehle, Anuscheh Nawaz, Georg Herdrich, Stefanos Fasoulas, Edward Martinez, and George Raiche. Comparison of Heat Flux Gages for High Enthalpy Flows - NASA Ames and IRS. In AIAA, Washington, 2016. 